\title{
Function-Integrative Textile Reinforced Concrete Shells
}

\author{
Sandra Gelbrich, Henrik L. Funke, Lothar Kroll \\ Institute of Lightweight Structures, Technische Universität Chemnitz, Chemnitz, Germany \\ Email: sandra.gelbrich@mb.tu-chemnitz.de
}

How to cite this paper: Gelbrich, S., Funke, H.L. and Kroll, L. (2018) Function-Integrative Textile Reinforced Concrete Shells. Open Journal of Composite Materials, 8, 161-174. https://doi.org/10.4236/ojcm.2018.84013

Received: September 5, 2018

Accepted: October 27, 2018

Published: October 30, 2018

Copyright $\odot 2018$ by authors and Scientific Research Publishing Inc. This work is licensed under the Creative Commons Attribution International License (CC BY 4.0).

http://creativecommons.org/licenses/by/4.0/

(c) (i) Open Access

\begin{abstract}
This paper presents the development and technological implementation of textile reinforced concrete (TRC) shells with integrated functions, such as illumination and light control. In that regard the establishment of material, structural and technological foundations along the entire value chain are of central importance: From the light-weight design idea to the demonstrator and reference object, to the technological implementation for the transfer of the research results into practice. The development of the material included the requirement-oriented composition of a high-strength fine grained concrete with an integrated textile reinforcement, such as carbon knitted fabrics. Innovations in formwork solutions provide new possibilities for concrete constructions. So, a bionic optimized shape of the pavilion was developed, realized by four connected TRC-lightweight-shells. The thin-walled TRC-shells were manufactured with a formwork made of glass-fibre reinforced polymer (GFRP). An advantage of the GFRP-formwork is the freedom of design concerning the formwork shape. Moreover, an excellent concrete quality can be achieved, while the production of the precast concrete components is simple and efficient simultaneously. After the production the new TRC-shells were installed and assembled on the campus of TU-Chemnitz. A special feature of the research pavilions are the LED light strips integrated in the shell elements, providing homogeneous illumination.
\end{abstract}

\section{Keywords}

Textile Reinforced Concrete, Carbon Reinforced Concrete, Textile Reinforced Composites, Function-Integrated Lightweight Structures, Glass-Fibre Reinforced Polymer Formwork, Thin-Walled Shells

\section{Introduction}

In the middle of last century, architects like Felix Candela and Heinz Isler have 
already built a large number of lightweight shell structures made of reinforced concrete. The results of their works are thin-walled structures featuring a particularly advantageous load bearing behavior in respect of the building material concrete. However, the corrosion problems of reinforcing steel in filigree structural elements with very small concrete cover as well as the complex and expensive formwork, were an obstacle to further applications of this resource-conserving construction method.

In the last few years, lightweight construction has gained more and more importance as a result of resource saving. This makes lightweight construction to one of the key technologies in many sectors of industry and comprises the use of resource- and energy-efficient components and constructions with load-bearing properties. Decisive prerequisites for the application of light-weight construction are highly load-bearing materials, filigree load-adapted structures and integrated systems for monitoring.

Concepts of lightweight construction are:

- The substitution of materials of higher density by lighter composite materials while retaining or increasing strength and stiffness properties.

- Weight reduction of the construction carried out by structural optimization of the components and constructions using lightweight geometric shapes dimensioned according their main direction of stress. Special consideration must be given to the join connections.

- The development of multifunctional lightweight constructions, which combine load-bearing properties with other functions (insulation, lighting, monitoring).

The application of lightweight constructions is now more important than ever, since current trends in architecture are strongly influenced by free form-finding, resource efficiency and functional integration. This is where conventional building materials (steel or reinforced concrete) reach their limits. In order to implement the new free-formed architecture, high-performance, multifunctional materials and efficient manufacturing technologies are required. For this purpose, new lightweight composites (e.g. textile reinforced) concrete offer decisive advantages.

In the last couple of years, research in the fields of innovative concrete structures with high degree of lightweight design, and of textile reinforcement for special applications has been objective of intensive scientific and application-oriented efforts [1] [2] [3]. But, there is a lack of appropriate formwork systems to implement light shell structures of this kind, with the need for flexible mouldable, reusable systems being particularly tense [4]. Textile reinforced concrete offers a high range of variation and thus facilitates a flexible adjustment of form and textile reinforcement (e.g. [5] and the citations listed there). Another advantage in comparison to ordinary reinforced concrete is that corrosion can be largely excluded. In this way, filigree constructions of minimal thickness can be realized [6] [7] [8].

A crucial technological objective of textile reinforced concrete elements is the 
development of complex solid preform-structures. These are produced by processing flat structures through appropriate cutting [9]. The soft-elastic behaviour of the 3D-textiles can be influenced to a large extent by modifying parameters such as stiffness, alignment and concentration of pile threads. Thus, it can be adjusted to the defined curvature. Although selectively deformable textile 3D-structures for the reinforcement of concrete lightweight elements exist, for instance spacer fabric; the corresponding formwork elements are only in an early stage of development. These elements are essential for the realization of concrete shell structures that can be curved in any way.

Currently, possible shapes of shell structures are that of domes, hyperbolic paraboloids and conoids. But their production entails a considerable amount of material and high costs, besides the difficult mathematical description of the predetermined complex freeform surfaces and the anisotropic material characteristic [4] [10] and [11] [12] [13].

In the field of computer-aided visualization, different methods have been developed for the shape optimization of surfaces and their static construction calculation and design [14]. However, these technologies were until now not applied in the formwork production [15]. Among the common formwork techniques are conventionally segmented steel and wood systems, pneumatically supported and modeled formworks in various combinations [16] [17].

As previously described, the innovative composite material TRC offers a high degree of lightweight potential compared to the classic building materials. This introduces new fields of application with regard to filigree structures in architecture. By using corrosion-resistant textile reinforcement made of alkali-resistant glass or carbon, the concrete covering can be decimated, allowing a permanent and sustainable implementation of slim concrete components [18]. In order to broaden the application spectrum from TRC plates to freely-shaped support structures, new methods for design and material composition, calculation algorithms and production technologies are required. Therefore, the development and technological implementation of thin-walled TRC-shells was topic of comprehensive research activities at the Department of Lightweight Structures and Polymer Technology of Chemnitz University of Technology [19] [20] [21] [22].

The research presented in this paper illustrates the holistic approach: from form-finding and bionic optimization-process, over material composition and load-adapted dimensioning, to manufacturing technology and function-integration (Figure 1). In this regard the establishment of material, structural and technological foundations along the entire value chain and transfer of the research results into practice are of central importance.

\section{Material Composition and Characteristics}

\subsection{Materials}

The development of the fine grained concrete was focused on the workability of the fresh concrete as well as the durability and good bonding between concrete 


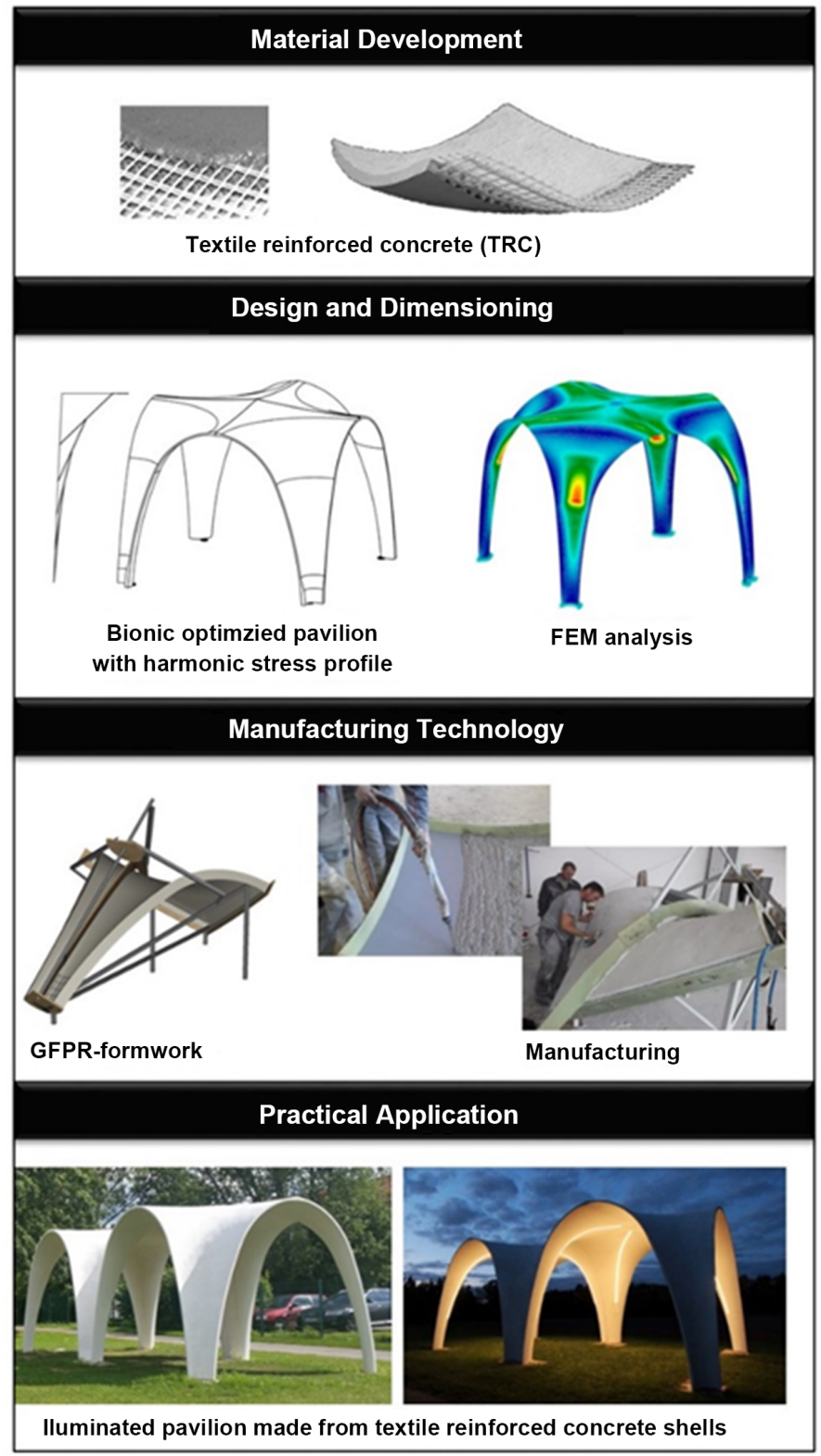

Figure 1. Development and implementation of function-integrative textile reinforced concrete shells-overview.

matrix and textile reinforcement. In Table 1 the qualitative and quantitative composition of the developed and optimized fine grained concrete mix is shown.

Apart from white Portland cement type 52.5 R, the fine concrete contained an amorphous aluminosilicate as puzzolanic binder. Dolomite sand with a grain size of 1 to 3 and 0.5 to $1.0 \mathrm{~mm}$ was used as aggregate and dolomite powder with an average grain size of $70 \mu \mathrm{m}$ was used as filler. Furthermore, integral alkali-resistant (AR) short glass fibres $(12 \mathrm{~mm}, 45 \mathrm{tex})$ were added in order to increase the early-age cracking resistance. Additional additives used were a high-performance superplasticizer based on polycarboxylate ether (PCE), a retarding agent and cementing agent. The fine-aggregate concrete mixture was 
Table 1. Composition of fine grained concrete mix.

\begin{tabular}{cc}
\hline Component & Content in $\mathrm{kg} / \mathrm{m}^{3}$ \\
\hline White cement CEM I 52.5 R & 530 \\
Amorphous aluminosilicate & 120 \\
Dolomite sand 1/3 & 330 \\
Dolomite sand 0.5/1.0 & 900 \\
Dolomite filler $\left(x_{50}=70 \mu \mathrm{m}\right)$ & 150 \\
Water & 250 \\
AR-glass fibres $(12 \mathrm{~mm}$, integral $)$ & 17 \\
Superplasticizers & 10 \\
\hline
\end{tabular}

formulated with a water-cement-ratio of $\mathrm{w} / \mathrm{c}=0.40$ for the application by trowel as well as spraying.

The fine grained concrete was mixed with the intensive mixer Eirich R05T. The mixing time was $5 \mathrm{~min}$ in total. The mixing parameters in detail were:

Addition of

1) Binders and aggregates: counter rotation for $60 \mathrm{~s}$;

2) $75 \%$ of water: co-rotation for $90 \mathrm{~s}$;

3) Super plasticizer: co-rotation for $60 \mathrm{~s}$;

4) Residual water: co-rotation for $30 \mathrm{~s}$;

5) AR-glass fibres: co-rotation for $60 \mathrm{~s}$.

For the production of the textile reinforced concrete elements, the carbon fibre textile "Sigratex Grid" (by SGL Group) with a roving fineness of 1800 tex as well as an impregnation content of $20 \mathrm{wt} . \%$ was used for reinforcing the fineaggregate concrete matrix.

\subsection{Characteristics}

The fresh concrete was tested according to DIN EN 12350. Air content and bulk density of the fresh concrete were determined by means of an air content testing device, following DIN 18555-2. The specimen needed for the tests that are to be performed on the hardened concrete were stored dry, according to DIN EN 12390-2. The 3-point bending tensile strength (Figure 2(a)) was determined by means of the Toni Technik on samples measuring $225 \times 50 \times 15 \mathrm{~mm}^{3}$, based on DIN EN 12390-5. The span width was set to $200 \mathrm{~mm}$ and the load speed $100 \mathrm{~N} / \mathrm{s}$, constant. The compressive strength was determined by means of the Toni Technik (load frame $3000 \mathrm{kN}$ ) following DIN EN 12390-3, with cubes having an edge length of $150 \mathrm{~mm}$ (Figure 2(b)). The pre-load was $18 \mathrm{kN}$.

To validate the durability of the fine grained concrete, the capillary suction of de-icing solution and freeze thaw test (CDF-Test) was measured by the Schleibinger Freeze-Thaw-Tester with standard agent solution according to the recommendations of RILEM TC 117-FDC (Figure 2(c), Figure 2(d)).

Table 2 shows the characteristics of fresh concrete opposed to hardened concrete after 28 days. 


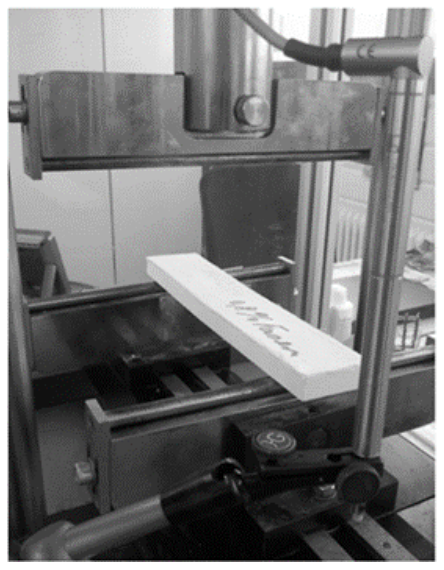

(a)

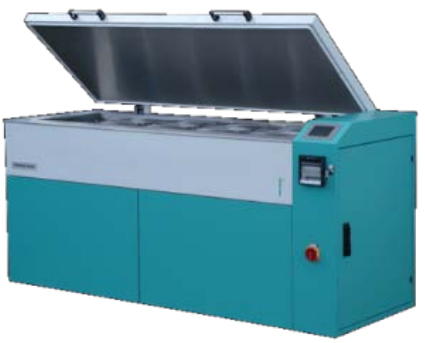

(c)

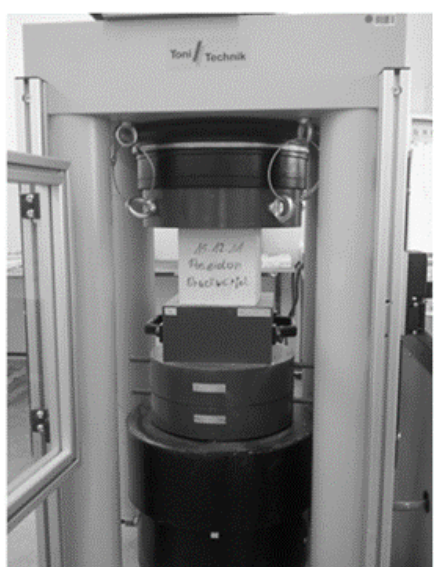

(b)

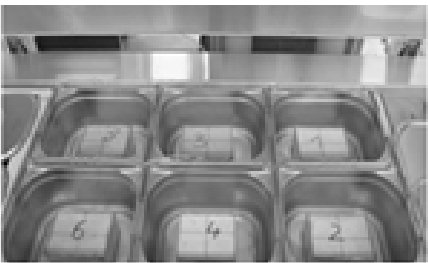

(d)

Figure 2. (a)Determination of 3-point bending tensile strength and (b) compressive strength, (c) Determination of the capillary suction of de-icing solution and freeze thaw (CDF)-test, (d) Schleibinger Freeze-Thaw-Tester.

Table 2. Characteristics of fresh and hardened fine grained concrete after 28 days.

\begin{tabular}{ccc}
\hline characteristic & fresh concrete & hardened concrete \\
\hline geometric bulk density & $2.29 \mathrm{~g} / \mathrm{cm}^{3}$ & $2.24 \mathrm{~g} / \mathrm{cm}^{3}$ \\
air content & $4.0 \mathrm{Vol} . \%$ & - \\
linear shrinkage & $0.71 \mathrm{~mm} / \mathrm{m}$ & $0.71 \mathrm{~mm} / \mathrm{m}$ \\
compressive strength & - & $131 \mathrm{MPa}$ \\
3-point bending tensile strength & - & $45 \mathrm{MPa}$ \\
CDF-Test & - & $\mathrm{m}_{28}=528 \mathrm{~g} / \mathrm{m}^{2}$ \\
$\mathrm{R}_{\mathrm{u}, 28}=96 \%$
\end{tabular}

Experimental studies determined a compressive strength and three-point bending tensile strength of $131 \mathrm{Mpa}$ and $45 \mathrm{MPa}$ respectively after 28 days for a carbon-fibre reinforced concrete. Apart from the high strength, small minimum concrete cover and the high surface quality, carbon-fibre reinforced concrete features a good durability, determined at a mean scaling of $528 \mathrm{~g} / \mathrm{m}^{2}$ and a relative dynamic-modulus of $96 \%$ after 28 freeze-thaw cycles by means of the CDF test method. Hence, the fine-aggregate concrete met the requirements on freeze 
resistance with high water saturation and de-icing agent (XF4).

\section{Form-Finding Based on Bionic Methods}

For the efficient production of textile concrete shell structures the technology-oriented form-finding is of particular importance. In order to achieve comparatively low tooling costs during manufacture as well as a high degree of pre-production, modular designs are the focus of developments works. In the case of suitable segmented form and function, standardized individual components can be combined and used as a whole, for example in shell construction.

Many biological constructions are based on the shell construction principle and lead to particularly effective and light structures. This includes elements that are form-stable, statically optimized and multifunctional, and can be built with less material usage. Examples are shells of shells or sea urchin.

In order to technologically implement the organically shaped textile concrete shells according to nature, modular double curved roofing elements were developed-inspired by petal leaf structures (Figure 3(a)). The design of the modularized shell construction is based on optimization processes for form-finding with the aim of transmitting maximum forces over defined spans with minimal mass. A rotationally symmetrical basic shape has been developed for the efficient production of the thin-walled shell elements.

The adaption of the research pavilions concerning the mechanical properties of TRC is based on an optimization of the distribution of stress using the tensile triangles according to Claus Mattheck, and results in a harmonious stress flow in the range of radius transitions (Figure $3(\mathrm{~b})$ ).

This bionical optimized shape of the pavilion is implemented by four TRC-shells that are connected to each other. The rotational symmetry of the shape requires just one single formwork for the production of the pavilion, with the dimensions of $4 \mathrm{~m} \times 4 \mathrm{~m} \times 3 \mathrm{~m}(1 \times \mathrm{w} \times \mathrm{h})$. The four individual TRC-shells with material thicknesses of about $30 \mathrm{~mm}$ are bonded by means of a tongue and groove system that is connected with positive locking and glued together with a mineral adhesive.

\section{Manufacturing at the Precast Concrete Plant}

\subsection{GFRP-Formwork}

The thin-walled carbon-fibre reinforced concrete shells were manufactured with a formwork system made of glass-fibre reinforced polymer. An advantage of this GFRP formwork is the freedom of design in regard to the formwork shape. Moreover, an excellent concrete quality in the highest class of architectural concrete can be achieved, while the production of the precast concrete components is simple and efficient simultaneously.

A formwork system, consisting of a flexible multi-layered GRP mould with side edges and a steel substructure, was constructed for the production of the reference pavilion. Uniform concrete cover was ensured by the installation of a 

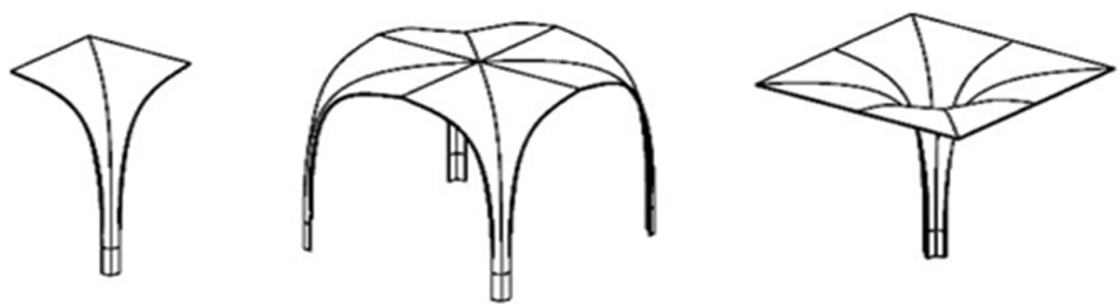

(a)
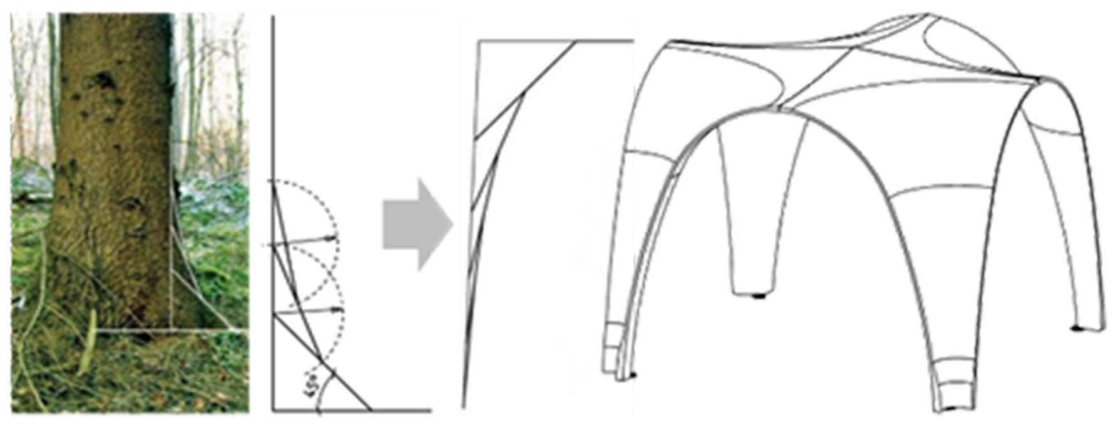

Tensile triangles at tree trunk $\rightarrow$ Bionic optimized pavilion with harmonoius stress flow

(b)

Figure 3. (a) Design of a single element, examples for modular shells, (b) Form-finding based on bionic methods.

doctor blade system, whereby the fine concrete matrix could be peeled off in layers and thus compensated for (Figure 4).

\subsection{Spacer for Textile Reinforcement}

Spacers are used to position the reinforcement in the concrete. Because of the different concrete cover $\left(\mathrm{c}_{\mathrm{TRC}} \leq 5 \mathrm{~mm}, \mathrm{c}_{\mathrm{SRC}}=15-50 \mathrm{~mm}\right)$ as well as the considerably smaller diameter of reinforcement textiles $(\mathrm{d} \leq 3 \mathrm{~mm})$ compared to steel reinforcements $(\mathrm{d}=6-30 \mathrm{~mm})$ classic spacers are not suitable. There for two polymer-based spacers have been developed for the position-appropriate integration and fixing of textile reinforcement in the concrete matrix: "C-texClip" and "C-tex-Spacer" (Figure 5). "C-texClip" is used to fix the textile reinforcement during the concreting process with a defined distance of the formwork. The "C-tex-Spacer" was created as a spacer for textile reinforcement, in order to arrange two textile reinforcement girders with a defined distance to each other in the formwork. For the tests the new spacers were manufactured by using 3D printing technology. The positioning aids are fixed at the intersections of the weft and warp threads of the carbon-fibre textiles by means of undercuts, thus allowing a defined concrete cover.

This way, the reinforcement of the precast concrete component can be placed in the exact position without any reinforcement being visible on the surface.

\subsection{Concreting}

The textile-reinforced shell elements were manufactured from a white, smooth concrete with an integrated layer of carbon reinforcement (girder). For concreting 

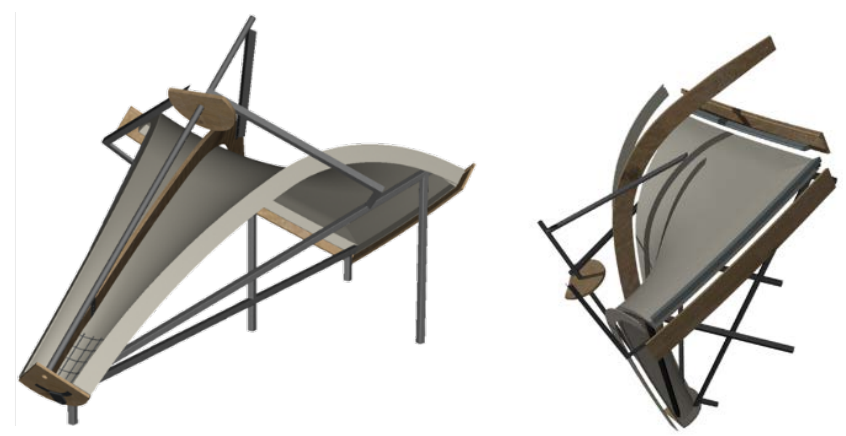

Figure 4. Developed GFRP-formwork with the doctor blade system.
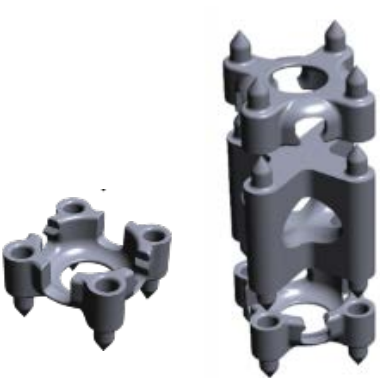

(a)

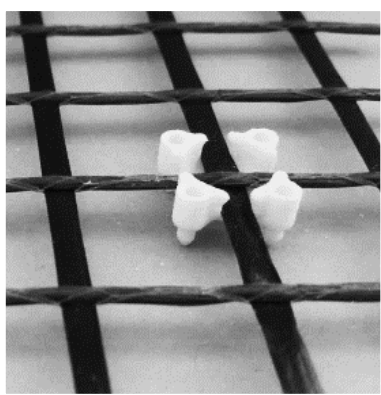

(b)

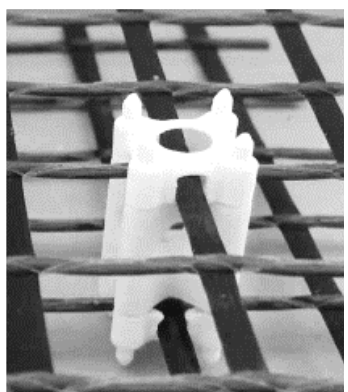

(c)

Figure 5. (a) "C-texClip", (b)Modular "C-tex-Spacer", (c) "C-texClip" in textile girder, (d) "C-tex-Spacer" between 2 textile girders.

and realizing a high surface quality, the new flexible GRP formwork with the doctor blade system was used. In a first step, the resin-coated carbon reinforcement was introduced into the GFRP-formwork and preformed. After hardening, the preformed carbon reinforcement was removed from the formwork and the new spacers (C-texClip) were fixed on the intersections of the weft and warp threads of the carbon textile. The C-texClips were used to position the textile reinforcement exactly in the concrete. Subsequent, the prepared reinforcement was placed in the GFRP-formwork once again and the concreting was carried out in a next step. This was done manually layer by layer. Then the final fine-aggregate concrete layer is placed. After the hardening, the formwork was stripped.

\section{Results-Reference Object}

For the transfer of the development results into practice, research pavilions made of carbon-fibre reinforced concrete were installed on the campus site at Chemnitz University of Technology. For this purpose, four rotationally symmetrical elements were connected to each other by gluing in combination with a tongue-and-groove connection. Integrated stainless steel components in the foot segments provide the fastening to the foundation.

\subsection{Dimensioning}

The dimensioning was carried out according to the limit state of load-bearing 
capacity (stress analysis) and serviceability limit state (permissible displacement). The required material parameters for the calculation were determined experimentally. For the finite element simulation the discretization of the pavilion took place via evenly distributed quad elements, which are supported by spring elements with a defined spring stiffness.

As a result, a maximum tensile stress of $4.46 \mathrm{MPa}$ was detected, which occurs in the middle of the elements and in the foot areas. The maximum compressive stress of $4.71 \mathrm{MPa}$ is located in the middle of the elements (Figure 6). This is far below the tolerable compressive stress of $56.7 \mathrm{MPa}$.

\subsection{Construction of Research Pavilion}

With the collaboration of the two German companies: Fiber-Tech Group and Hentschke Bau $\mathrm{GmbH}$, research pavilions consisting of carbon-fibre reinforced concrete were built as lightweight shells with functional integration on the campus of the TU Chemnitz in order to transfer the scientific investigations into practice. The construction and assembly of the TRC-pavilion took place with the help of a mobile crane (Figure 7).

\subsection{Design and Functional Integration}

A special feature of the research pavilions are the LED light strips that are integrated in the shell elements, providing a homogeneous distribution of light and allowing an energy-efficient integration of the lighting system.

Textile sensors, produced in an embroidery process in the shape of a hand, are integrated in the shell structures as semi-finished fibre materials. Contrary to conventional sensor designs, this allows an integration of the sensors into the material directly, offering new design possibilities. The system is based on electrodes and/or antennas, which create a spatially limited, electrical field. Changes of the field are registered by touch of the shell element and the cascaded signal processing electronics creates a switch signal by feedback. Therefore, it is possible to set various lighting scenes and actively control them with the aid of these special touch sensors using an especially adapted control system (Figure 7).

\section{Conclusions}

The innovative composite material TRC offers a high degree of lightweight potential, compared to the classic building materials, especially for application in filigree structures. Through the use of the corrosion-resistant carbon textile reinforcement, the concrete covering will be decimated, making it possible to implement slim concrete components permanently and sustainably. For an increment of the application spectrum from textile-reinforced plates to freely-shaped support structures, new methods for material composition and production technology are required. This paper proposes a holistically concept from the development over the technological implementation and realization of textile reinforced concrete shells with integrated functions, such as illumination 


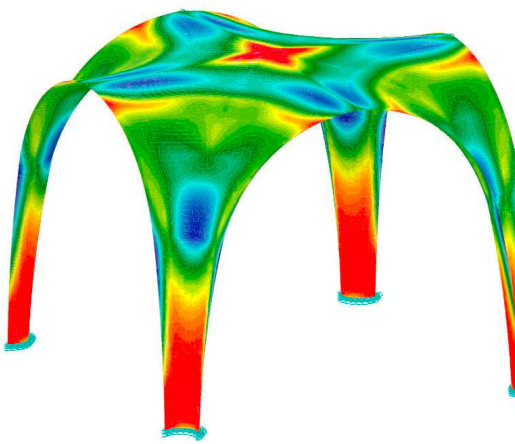

(a)

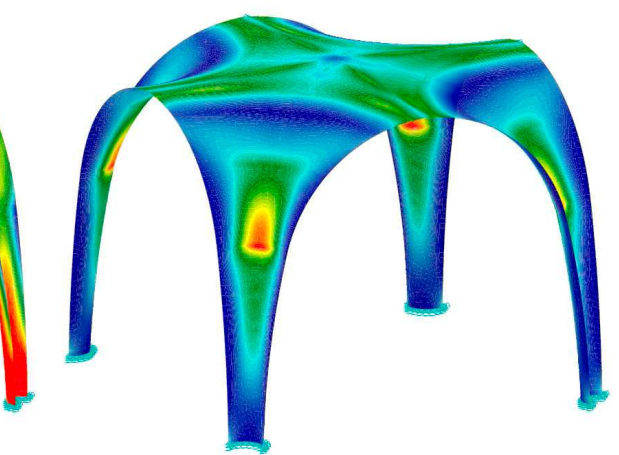

(b)

Figure 6. Results FE-analysis, (a) Tensile stress, (b) Compressive stress. In addition, a maximum displacement of $2.07 \mathrm{~mm}$ was calculated with the most unfavourable load combination, but this is not critical (further in [19]).

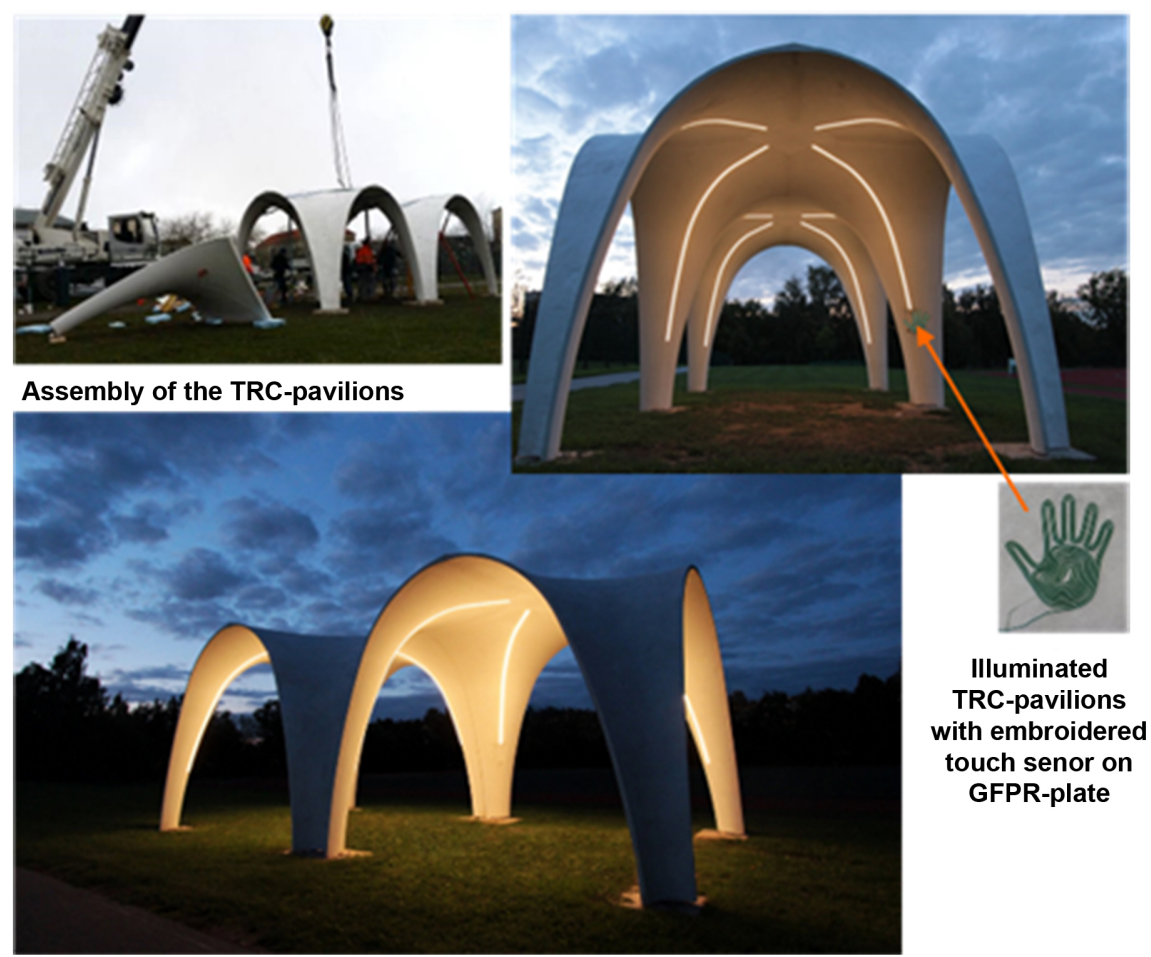

Figure 7. Function-integrative TRC-pavilion with LED lighting, operation via integrated sensors.

and light control. In this connection the establishment of material, structural and technological foundations was of central importance: From the lightweight design idea over the demonstrator and reference object to the technological implementation of the research results into practice.

The development of the material included the requirement-oriented composition of a high-strength fine grained concrete with an integrated carbon textile reinforcement. For this purpose a fine-grained concrete mixture was designed for the application by trowel as well as spraying. White alumino-silicate minerals as puzzolanic addition were used besides white cement CEM I $52.5 \mathrm{R}$. The ag- 
gregates used contain both dolomite sand and dolomite powder. Furthermore, integral short AR-glass fibres were added in order to increase the early-age cracking resistance. Additional additives used were a high-performance superplasticizer (PCE), a retarding agent and sealing agent. The integrated carbon knitted fabrics were used for reinforcing the fine-grained concrete. Compressive strength and three-point bending tensile strength of $131 \mathrm{Mpa}$ and $45 \mathrm{MPa}$ for the TRC with integrated carbon knitted fabric were determined in the following experimental studies. Apart from the high strength, small minimum concrete cover and the high surface quality, the new carbon concrete shells feature a good durability.

For an efficient technological implementation of shell elements the optimization of the distribution of stress using the tensile triangles according to Claus Mattheck offers great potential. The bionic inspired improvement of shell shapes resulted in a harmonious stress flow in the range of radius transitions of the connected shell elements. Thus, the TRC shells can be designed thinner and structurally more efficient.

The developed GFRP-formwork has proven its potential for application in TRC-shell manufacturing, by offering flexibility for the design, a high surface quality of TRC and reusability. Furthermore, the formwork is easy to master and efficient simultaneously during the production of the precast concrete components. Besides, the new GFRP-formwork can be used for the preforming of the textile reinforcements before concreting. Moreover, the manufacturing process was significantly facilitated due to the used GFPR-formwork, the preformed textile and the optimized fine grained concrete.

In order to validate the research results and transfer the development into the practice, research pavilions were established on the campus of Chemnitz University of Technology.

A special feature of the research pavilions are the LED light strips that are integrated in the shell elements, providing homogeneous illumination and allowing an energy-efficient integration and control of the lighting system.

In conclusion, the developed thin-walled TRC-shells are distinguished by their high resistance to weathering influences (durability), high surface quality and high load-bearing capacity. With regard to its free formability, this type of construction is particularly suitable for filigree, lightweight buildings. Due to the use of lightweight materials in combination with load-bearing textile reinforcement structures, this results in a shell construction which allows saving of material resources and a reduction in the dead weight. The additional integration of an interactive lighting function allows to further exploit the potential of the new textile construction in terms of functionalization.

\section{Acknowledgements}

This research project was supported by the Deutsche Forschungsgemeinschaft (DFG German Research Foundation), Federal Cluster of Excellence EXC 1075 "MERGE Technologies for Multifunctional Lightweight Structures" and the Eu- 
ropean Social Fund (SAB, Sächsische Aufbaubank). The authors would like to acknowledge with gratitude the foundation's financial support. We also want to thank Hentschke Bau GmbH, Fiber-Tech Products GmbH, Müller \& Pfeiffer $\mathrm{GmbH}$ und Steinbeis-Innovationszentrum FiberCrete, who supported the project.

\section{Conflicts of Interest}

The authors declare no conflicts of interest regarding the publication of this paper.

\section{References}

[1] Curbach, M. and Scheerer, S. (2011) Concrete Light-Possibilities and Visions. Proceedings of the Fib Symposium: Concrete Engineering for Excellence and Efficiency, 8-10 June 2011, 29-44.

[2] Brameshuber, W. (2006) Textile Reinforced Concrete. State-of-the-Art Report of RILEM Technical Committee, TC 201-TRC, RILEM Report 36.

[3] Funke, H., Gelbrich, S., Ehrlich, A. and Kroll, L. (2014) Rheological and Mechanical Development of a Fiber-Reinforced Concrete for an Application in Civil Engineering. SOJ Materials Science \& Engineering, 2, 1-4. https://doi.org/10.15226/sojmse.2014.00111

[4] Hofstadler, C. (2008) Schalarbeiten. Springer-Verlag, Berlin.

[5] Curbach, M. and Jesse, F. (2010) Verstärken mit Textilbeton. In: Bergmeister, K., Fingerloosand, F. and Wörner, J.-D., Eds., Betonkalender 2010, Teil 1, Abschn. VII, Ernst \& Sohn, Berlin.

[6] Funke, H., Gelbrich, S., Ehrlich, A. and Kroll, L. (2014) A Fibre-Reinforced Architectural Concrete for the Newly Designed Façade of the Poseidon Building in Frankfurt am Main. Journal of Materials Science Research, 3, 33-39. https://doi.org/10.5539/jmsr.v3n3p33

[7] Greiner, S. (2007) Zum Tragverhalten von Schalen aus ultrahochfestem FaserfeinKornbeton (UHFFB). Beton- und Stahlbetonbau, 100, 77-80.

[8] Funke, H., Gelbrich, S. and Ehrlich, A. (2013) Development of a New Hybrid Material of Textile Reinforced Concrete and Glass Fibre Reinforced Plastic. Procedia Materials Science, 2, 103-110. https://doi.org/10.1016/j.mspro.2013.02.013

[9] Curbach, M., Ortlepp, S., Brückner, A., Kratz, M., Offermann, P. and Engler, T. (2003) Entwicklung einer großformatigen, dünnwandigen, textilbewehrten Fassadenplatte. Beton- und Stahlbetonbau, 98, 345-350.

https://doi.org/10.1002/best.200301720

[10] Preisinger, C., Harrer, J., Ressl, C. and Kollegger, J. (2005) Stahlbetonschalen ohne Schalung-Ein neuer Weg im Schalenbau. Beton- und Stahlbetonbau, 100, 31-38. https://doi.org/10.1002/best.200590005

[11] Herzog, T. and Moro, J.L. (1992) Gespräch mit Felix Candela. Arcus 18: Zum Werk von Felix Candela-Die Kunst der leichten Schalen. Verlagsgesellschaft Rudolph Müller, Köln, 10-22.

[12] Kroll, L. (2005) Berechnung und technische Nutzung von anisotropiebedingten Werkstoff-Und Struktureffekten für multifunktionale Leichtbauanwendungen, Habilitationsschrift, TU Dresden, Dresden.

[13] Kaufmann, J. (2014) Beitrag zu anisotropiebedingten Koppeleffekten bei Rotations- 
Symmetrischen mehrschichtigen Faserverbundbauteilen. Promotionsschrift, TU Chemnitz, Chemnitz,.

[14] Kazakisa, G., Kanellopoulosa, I., Sotiropoulosa, S. and Lagarosab, N.D. (2017) Topology Optimization Aided Structural Design: Interpretation, Computational Aspects and 3D Printing. Heliyon, 3, e00431. https://doi.org/10.1016/j.heliyon.2017.e00431

[15] Dallinger, S., Pardatscher, H. and Kollegger, J. (2009) Zweifach gekrümmte Schalen aus Betonfertigteilen. Forschung \& Entwicklung für Zement und Beton, 5, 32-33.

[16] Zapf, W. (1990) Schalung für großformatige gekrümmte Stahlbetonfertigteile. German Patent: DE 3841579 A1.

[17] Henri, V. (1987) Verfahren und Vorrichtung zum Formen von gebogenen Sektionen aus Beton. European Patent: EP 0238168 A1.

[18] Funke, H., Gelbrich, S., Ehrlich, A. and Kroll, L. (2016) High Performance Textile-Reinforced Concrete Noise Barrier. In: Global Congress \& Expo on Material Science \& Nanoscience, 9th Edition, Dubai (VAE), 35.

[19] Gelbrich, S. (2017) Funktionsintegrative Leichtbaustrukturen für Tragwerke im Bauwesen. Habilitation; Universitätsverlag Chemnitz.

[20] Funke, H., Gelbrich, S. and Ehrlich, A. (2014) Textile Reinforced Concrete and Glass Fiber Reinforced Plastic-A New Hybrid Material for Lightweight Structures in Civil Engineering. 1 st Concrete Innovation Conference, Oslo, 38.

[21] Gelbrich, S., Ehrlich, A., Petzoldt, C. and Kroll, L. (2014) Flexible Fibre Reinforced Plastic-Formworks for the Production of Curved Textile Reinforced Concrete. In: El-Hacha, R., Ed., Proceedings of 7 th International Conference on Fiber Reinforced Polymer Composites in Civil Engineering, Vancouver, 101.

[22] Funke, H., Gelbrich, S., Ulke-Winter, L., Ehrlich, A. and Kroll, L. (2015) A Novel Flexible and Adjust Table Fibre-Reinforced Plastic Formwork Technology for Freeform Textile Reinforced Concrete Elements. In: KIVI, Ed., Proceedings of the International Association for Shell and Spatial Structures, Amsterdam, Paper No. IASS2015-479199. 